\title{
Casa, Intimidade e Cuidado: Experiências no Projeto Delicadas Coreografias
}

Home, Intimacy and Care: Experiences in the Project Delicates Choreographies

Casa, Intimidad y Cuidado: Experiencias em el Proyecto Delicadas Coreografias

\section{Beatriz Borges de Oliveira}

Flávia Liberman

Universidade Federal de São Paulo (UNIFESP), São Paulo, SP, Brasil

\section{Luciana Vieira Caliman}

Universidade Federal do Espírito Santo (UFES), Vitória, ES, Brasil

\begin{abstract}
Resumo
Este artigo apresenta alguns resultados de uma pesquisa que buscou colocar em análise experiências "nas casas", desenvolvida no projeto de extensão Delicadas Coreografias, durante o ano de 2018, na Universidade Federal de São Paulo, campus Baixada Santista. Foram realizados encontros semanais de estudantes extensionistas nas casas de um grupo de mulheres em situação de vulnerabilidade social, sofrimento psíquico, limitações físicomotoras, entre outras, todas residentes na cidade de Santos-SP. Tomamos como superfície de análise a experiência vivida nestes encontros, registrada em diários de campo elaborados pelas extensionistas. Conclui-se que a construção de espaços compartilhados de intimidade, afeto, formação de vínculos e a valorização dos pequenos acontecimentos/deslocamentos, podem se configurar como uma direção basilar na produção do cuidado em saúde que tem como aposta a afirmação dos processos de diferenciação.
\end{abstract}

Palavras-chave: Intimidade; Casa; Mulheres; Cuidado.

\begin{abstract}
This article presents some results of a research that put in to analysis experiences "in homes", developed in the extension Project Delicates Choreographies during the year of 2018, in Federal University of São Paulo, campus Baixada Santista. Weekly meetings of extension students were held in the houses of a group of women in a situation of social vulnerability, psychic suffering, physic and motor limitations, among others, all of them residing in the city of Santos, São Paulo. We took as na object of analysis the experience lived in these meetings, registered in field journals elaborated by the extension students. The conclusion was that the construction of shared spaces of intimacy, affection, bond formation and the valuation of small doings/ displacements, can be seen as essential to promote health care that bets on the affirmation of differential processes.
\end{abstract}

Key-words: Intimacy, Home, Women, Care. 


\section{Resumen}

Este artículo presenta algunos resultados de una investigación que busca poner em análisis una experiencias "en las casas", desarrollada em el proyecto de extensión Delicadas Coreografias, durante el año 2018, em la Universidad Federal de São Paulo, campus Baixada Santista. Se realizaron reuniones semanales de estudiantes de extensión em los hogares de un grupo de mujeres en situaciones de vulnerabilidad social, mal estar psicológico, limitaciones físicas y motoras, entre otras, todas las cuales Vivian em la ciudad de Santos-SP. Tomamos como superficie de análisis la experiencia vivida en estas reuniones, registrada en diarios de campo elaborados por extensionistas. Se concluye que laconstrucción de espacios compartidos de intimidad, afecto, formación de vínculos y La valoración de pequeños eventos/desplazamientos, puede verse como básica en la producción de un cuidado de la salud que tiene como meta la confirmación de los procesos de diferenciación.

Palabras clave:Intimidad; Casa; Mujer; Precaución.

Acho que o quintal onde a gente brincou é maior do que a cidade. A gente só descobre isso depois de grande. A gente descobre que o tamanho das coisas há que ser medido pela intimidade que temos com as coisas. há de ser como acontece com o amor. Assim, as pedrinhas do nosso quintal são sempre maiores do que as outras pedras do mundo. Justo pelo motivo da intimidade.(Barros, 2008, p. 67)

\section{Introdução}

O mundo enfrenta hoje a pandemia de COVID-19, sendo recomendadas pelas autoridades de saúde medidas de distanciamento físico para enfrentar o momento de crise. Das recomendações formuladas, sobressai a de ficar em casa para cumprir um período de quarentena, saindo apenas quando extremamente necessário. Com isso, a rotina das pessoas e suas relações com a casa mudaram. Para uma parte da população que tem condições socioeconômicas, com o home-office a casa tornou-se o ambiente de trabalho (Brum, 2020), enquanto que para outra grande parcela da população, estar em casa é uma impossibilidade. Para muitos estudantes, com o ensino remoto, a casa tornou-se escola. Com a videochamada 
com os amigos, intensificaram-se os encontros sociais agora atravessados mais do que nunca pelas atividades acadêmicas. Com as lives musicais, a casa passou a ser "a casa de shows". Podemos dizer, assim, que com a Pandemia houve inúmeras desacomodações e adaptações desiguais, singulares e diversas. Cabe ainda pontuar que para as pessoas que têm pouco ou nenhum acesso à internet, a casa transformou-se em lugar de "competição" por um único celular ou aparelho eletrônico para usos com diferentes fins, a depender do número de moradores e suas necessidades.

Nestes tempos pandêmicos, muitas casas revelaram-se, ainda, como local de ameaça, nos lembrando que nem todas as casas são acolhedoras - há casas ameaçadoras. Como é a experiência de quem precisa passar o período de isolamento em uma casa ameaçadora? No Rio Grande do Norte, de acordo com o Observatório de Violência do Estado, os casos de violência doméstica aumentaram $258 \%$ entre 12 e 18 de março de 2020, com relação ao mesmo período no ano anterior (Picinni\& Araújo, 2020). No Rio de Janeiro, segundo dados do Tribunal de Justiça do Estado, só no mês de março de 2020, os números de denúncias de violência doméstica e familiar aumentaram mais de 50\% (Picinni\& Araújo, 2020). O Ministério da Mulher, da Família e dos Direitos Humanos (Governo Federal, 2020) informou que as ligações para o canal de denúncia de violência contra a mulher aumentaram em 9\% só nos primeiros 15 dias de isolamento social, em março de 2020. Segundo o Ministério, o agressor é, na maioria das vezes, alguém da família ou próximo e o período de isolamento acaba obrigando mulheres a conviverem com seus agressores. A casa nem sempre é um lugar seguro.

Indo além na análise da experiência de estar em casa durante a quarentena, Carmen Silva em seu texto para a n-1 edições (2020), convida-nos a pensar como fica a situação de "quem não tem casa" no período em que a maior recomendação é “ficar em casa”. Quando as ruas estão vazias, estar em situação de rua sofre alterações consideráveis. É nas ruas cheias, com comércios abertos, que pessoas nessa situação conseguem comida, água, local para tomar banho e se trocar. Para estas pessoas, a rua é também casa e essa também sofre alterações consideráveis durante a vivência da pandemia. Por outro lado, na pandemia, há uma contração na circulação das pessoas pelas ruas, diminuindo significativamente o "seu lugar no mundo", a capacidade de manifestar, 
ocupar os espaços públicos e existir para os outros para que possam retornar às suas casas trazendo um mundo compartilhado, diverso e mutante fundamental nos processos de subjetivação (Sombini, 2020).

Arriscamos dizer, portanto, que, com todas as transformações em curso, o vínculo com a casa mudou. Não conseguimos ainda dimensionar as especificidades e singularidades das transformações experimentadas, nem todos os fatores que atravessam essa mudança. No entanto, talvez essa experiência global nos revele com mais intensidade que a casa é um lugar importante na constituição de nossos territórios existenciais e que estes também são mutantes, localizados no tempo e no espaço, dependentes das composições macro e micropolíticas que nos atravessam, dos vínculos que nos constituem.

Neste artigo, tomamos como superfície de análise algumas ações realizadas no período anterior à pandemia de COVID-19, que teve a casa e as relações que a atravessam como ponto central. Essas ações faziam parte do projeto de extensão "Delicadas Coreografias", vinculado a Universidade Federal de São Paulo, campus Baixada Santista, que atua em composição com o módulo Clínica Integrada: Produção de Rev. Polis e Psique, 2021; 11(3): 230 - 254
Cuidado, do eixo comum Trabalho em Saúde (TS) e no território com o Instituto Arte no Dique.

O TS é um dos eixos comuns dos cursos de graduação do Instituto de Saúde e Sociedade da Universidade Federal de São Paulo, Campus Baixada Santista, que faz parte de uma proposta formativa interdisciplinar e interprofissional. Os módulos desse eixo têm como um dos objetivos compreender as múltiplas dimensões envolvidas no processo saúdedoença e na produção de cuidado. Já o Instituto Arte no Dique é uma organização sem fins lucrativos que desenvolve ações socioculturais, baseadas em pesquisa, inclusão social e valorização da cultura local.

O trabalho é feito com mulheres em situações de vulnerabilidade social, sofrimento psíquico e limitações físicomotoras - todas elas residentes na região noroeste da cidade de Santos, SP. O grupo de dez mulheres que integra o projeto existe há mais de dez anos e nele está estabelecido um vínculo afetivo, portanto, não cabem propostas de intervenção pontuais, curtas e imediatistas. Os encontros desse grupo, tanto com as extensionistas quanto com as alunas do módulo Trabalho em Saúde, ocorrem semanalmente. Optamos por privilegiar o 
uso de pronomes e adjetivos no gênero feminino, uma vez que as extensionistas e as estudantes envolvidas na experiência eram, em sua maioria, mulheres.

Ao longo do tempo, algumas mulheres do projeto preferiram não comparecer aos encontros realizados no Instituto Arte no Dique por diversos motivos: problemas de saúde, desmotivação, recusa. Ao mesmo tempo, no período de férias acadêmicas, sentiu-se a necessidade de sustentar o vínculo entre as extensionistas e as mulheres enquanto os módulos da universidade e as atividades no Instituto não aconteciam. Foi aí que se iniciou a proposta de entrada nas casas das mulheres: se elas não vão ao encontro, o encontro vai até elas. Assim, tiveram início as ações "nas casas" (Liberman \&Maximino, 2015). Nelas, as extensionistas fizeram encontros também semanais nas casas das mulheres, promovendo atividades além daquelas desenvolvidas no módulo da TS, para, assim, manter o vínculo grupal ativo e promover outras experiências artísticoformativas na produção de cuidado.

O principal objetivo deste artigo é, a partir da experiência vivida "nas casas", analisar a produção de espaços compartilhados de intimidade entre as participantes e seus efeitos na produção de cuidado em saúde, sob o olhar das extensionistas e das pesquisadoras, investigando como se dá a relação da entrada nas casas com a construção de vínculos e confiança. A nosso ver, a tessitura conjunta dos vínculos e das relações criadas durante os encontros está intimamente ligada à produção de cuidado em saúde. O cultivo da intimidade, do afeto, a construção de um ambiente confiável e a valorização de um trabalho artesanal que busca reconhecer e produzir pequenos deslocamentos, podem se configurar como uma direção basilar na produção de cuidado em saúde.

As ações realizadas com as mulheres são investigadas pelo Projeto Temático Delicadas Coreografias: Práticas artísticas e Corporais como Produção de Subjetividade, aprovado pelo Comitê de Ética em Pesquisa da UNIFESP sob o número CAAE: 65961417.4.0000.5505. As ações "nas casas" resultaram em um subprojeto de investigação do Projeto Temático. No texto foram utilizados os nomes reais das mulheres participantes, decisão tomada em consenso com todos os envolvidos na pesquisa.

\section{Metodologia}


A pesquisa das ações "nas casas" foi realizada a partir de uma abordagem qualitativa, orientada pelo método cartográfico (Souza \& Francisco, 2017). Os objetivos foram definidos a partir do caminho percorrido pela pesquisa realizada no projeto Delicadas Coreografias, e o que foi vivido dos encontros nas casas assumiu caráter interventista, afetando todas as envolvidas, pesquisadoras-extensionistasgrupo de mulheres (Souza \& Francisco, 2017). Para a escrita deste artigo, foi realizado um levantamento bibliográfico para familiarização com o problema investigado concomitante à análise dos diários de campo produzidos sobre os encontros realizados nas casas. É importante ressaltar que a alunapesquisadora, uma das autoras deste artigo, participou como extensionista de todos os encontros analisados, sendo uma das produtoras dos diários de campo.

Assim, foram utilizados 23 diários, focalizando a nossa atenção naqueles realizados nas casas de algumas das participantes ao longo do ano de 2018. Os diários de campo foram elaborados com notas descritivas e intensivas, registrando observações, impressões e afetações da experiência. Nas notas descritivas são colocados os dados objetivos dos encontros: local, quem estava presente, Rev. Polis e Psique, 2021; 11(3): 230 - 254 características dos presentes, descrição das situações. Nas notas intensivas são narradas as sensações que o encontro provocou, bem como as reflexões, os sentimentos e os desafios (Capozollo, Casetto\&Henz, 2013). É importante explicitar que a entrada em uma casa só acontecia mediante um convite - expressão de abertura e desejo manifesto de abrir a casa ao grupo. Assim, experimentava-se não apenas a abertura para entrar em uma casa e/ou receber o outro, mas também uma abertura à tessitura conjunta de espaços compartilhados de intimidade.

\section{Paisagem e duração dos encontros}

Podemos dizer que os encontros "nas casas" eram divididos em três partes: antes, durante e depois. No antes, surgiam algumas perguntas: Ligamos para todas as mulheres? Todas irão? E se chover? Como vamos sair da Zona Noroeste de Santos se lá sempre alaga? Qual será o lanche? Em qual horário iremos sair? Por qual itinerário conduziremos o motorista da van? $\mathrm{O}$ antes envolvia o planejamento. Primeiro, era necessário decidir na casa de quem faríamos o encontro. Depois, era preciso definir se seriam apenas com as extensionistas ou se as alunas do módulo estariam presentes também - o que 
dependia do calendário letivo e do planejamento do módulo. Os encontros que aconteciam nas casas foram, em sua maioria, durante o período de férias, ou enquanto as alunas do módulo estavam em atividades de supervisão. Durante as férias, não tínhamos o carro da universidade para nos levar e para buscar as mulheres, então precisávamos pensar em outras estratégias.

Os encontros aconteciam todas às quartas-feiras. Assim, já na segunda-feira começávamos a ligar para as mulheres para lembrá-las e era combinado o horário em que passaríamos para buscá-las. Na terçafeira, organizávamos o que cada uma levaria para o lanche. Dessa forma, não teríamos apenas doce ou salgado. Esse era o momento de passar no mercado e comprar algum ingrediente que faltava para preparar o lanche, ou ir à padaria para comprar algo pronto, caso estivesse com falta de tempo. Pensar no lanche, comprar ou preparar algo era um ato de cuidado - o pensar na comensalidade, que compunha o trabalho de sustentar e valorizar gestos menores de inclinar-se na direção do outro.

$\mathrm{Na}$ manhã que antecedia os encontros, os últimos detalhes eram acertados. As mensagens no celular eram constantes. Caso as alunas fossem, eram utilizadas duas vans. Era necessário fazer a divisão de quem ia em cada van, qual delas buscaria quais mulheres e o horário. A primeira van, que pegava um maior número de mulheres, saía 15 minutos antes. Algumas alunas e professores estavam em outra unidade da universidade, então era necessário buscá-los também. Todas essas ações compunham um processo que resultava no encontro propriamente dito no espaço das casas, mas tratava-se, sobretudo, de um trabalho artesanal no qual se aprendia perseverança, paciência e atenção ao pequeno (Liberman \& Maximino, 2015). A região Noroeste de Santos, território onde os encontros aconteciam, é marcada pela vulnerabilidade social, por ter, em sua maioria, muitas famílias vivendo em barracos de palafitas, sem nenhum saneamento básico. Deslocar-se da universidade até a casa das mulheres levava, em média, 30 minutos. A região conta com alguns canais e quando a maré está alta, mesmo sem chuva, as ruas alagam. Com chuva, a situação piora. Nos dias de fortes chuvas há o risco de alagamentos e, portanto, de não ser possível sair da região. Isso tudo era levado em conta antes de tomar a decisão de realizar ou não o encontro. Preparar-se para possíveis imprevisibilidades também era parte do planejamento. Nesse processo de organização, estávamos o tempo todo 
com a atenção voltada ao cuidado às mulheres, mas também às alunas, na reflexão sobre as condições mínimas e satisfatórias para que a experiência pudesse acontecer. Todo esse processo “(...) denuncia uma intenção que também faz parte do aprendizado: desenvolver um estado de presença e prontidão para adaptar-se rapidamente às novas situações, reorganizando a distribuição das tarefas pela leitura que se faz do momento." (Liberman \&Maximino, 2015, p. 122).

Durante o encontro, éramos tomados pelo calor e emoção do "estar junto". Por algumas horas, deixávamos de lado as preocupações - o que fazer para o jantar, se daria tempo de encontrar aquele amigo, os problemas familiares, as tarefas de casa e da Universidade - e estávamos realmente disponíveis para os encontros, para o cuidado em curso. $\mathrm{O}$ horário combinado com as mulheres era sempre por volta das 14 horas, em suas casas ou em um local próximo. A "colheita" das mulheres já era parte do encontro. Foi preciso aprender as rotas, qual caminho fazer para chegar às casas, qual mulher buscar primeiro, explicar para o motorista por onde seguir. (Liberman \&Maximino, 2016). Uma a uma, as mulheres entravam na van; algumas se misturando com as alunas, pois diziam querer estar perto e Rev. Polis e Psique, 2021; 11(3): 230 - 254 aprender com os mais jovens, não envelhecer, enquanto outras ficavam nos primeiros bancos, conversando entre si como amigas de longa data. Todas ansiosas para conhecer a casa da anfitriã do dia. Ao chegar na casa, havia um esforço atencioso para que todas se ajeitassem. A anfitriã sempre fazia questão de que todas ficassem à vontade e pedia para guardarmos os lanches na geladeira. Todos acomodados, partíamos, então, para a pergunta: “Como vocês estão?” Fugindo do óbvio "tudo bem", todas realmente falavam como estavam se sentindo, contavam algo que tinha acontecido na semana e como reagiram. Surgiam narrativas tristes e alegres, em inúmeras tonalidades emocionais - falas que despertavam outras falas, mulheres que se empoderavam com as palavras, com as possibilidades de se expressar e compartilhar um pouco daquilo que viviam.

Em todos os encontros, independentemente do tema proposto e do rumo da conversa, a música sempre se fazia presente - pelas extensionistas e alunas da TS que traziam uma playlist previamente planejada, no acionamento de instrumentos musicais trazidos aos encontros, mas também na cantoria que sempre acontecia e produzia aproximações 
entre todas. Este grupo em particular tem uma tonalidade musical bastante evidente, regando os encontros com músicas importantes em suas vidas, por letras que expressavam as emoções que gostariam de compartilhar, lembrar ou mesmo comunicar umas às outras. Com a música, vinha sempre a dança, mesmo considerando o contexto de limitações físico-motoras que algumas daquelas mulheres apresentavam. A dor nas pernas sumia, as cabeças balançavam no ritmo da música ou mesmo apenas na escuta das vozes e, tomados pelos ritmos, seus corpos podiam acionar um estado pulsante e mais vitalizado. Estes pequenos deslocamentos nos mostravam a todo o momento a potência dos pequenos acontecimentos partilhados, do simples, daquilo que pode parecer banal, mas que se configura como modos de habitar frestas, experimentar encontros amorosos e transformadores em cotidianos muitas vezes empobrecidos pelas condições de vida e escassez de oportunidades.

Neste sentido, consideramos que

(...) as artes com sua linguagem expressiva aliada a um grau de presença dos corpos acabam por produzir afetos e criações que se fazem muitas vezes por pequenos acontecimentos, pequenos deslocamentos na sua continuidade habitual, muitas vezes automatizada e desprovida de sentido permeando nossos cotidianos e nossa vida. (Liberman, Guzzo \& Lima, 2020, p. 207)

É inevitável falar algo sobre o momento musical do encontro, a música é a fé que me move, a fé que me guia. A hora em que Izabel (uma das estudantes) puxou "Fascinação" de Elis Regina fiquei arrepiado, ficava olhando o tempo todo para Carmen (uma das mulheres do grupo) cantando a música, lindo demais. Emendamos um samba, samba para curar a dor, para vibrar as cores e a essência de cada um ali presente. Sobrou até homenagem à Eunice (outra mulher do grupo) através de sua resistência política, assim como para Tânia (uma das mulheres), apaixonada por Tim Maia. Uma bela junção a partir do sentimento que pulsava no dedilhado do violão, o som aveludado do ukulele, o contraste do bongô e o sincopado do pandeiro. Pudemos percutir, e sobretudo repercutir os sons e os sonhos! Enfim, os instrumentos foram à campo! (Trecho de diário de campo) 
A potência da música ressoa no grupo e em cada uma permitindo a vivência e o acompanhamento de um ritmo relacional. Além disto, percebemos que a diferença geracional entre as estudantes e as mulheres também permitia tais trocas, mobilizadas pelas diferentes linguagens artísticas - o verbo, os cantos, as danças e seus movimentos, mas também as pausas e os silêncios.

Ao final de cada encontro, fazia-se o lanche.

Abrir a geladeira, colocar a mesa, pegar o pó e o açúcar no armário para fazer o café, servir quem teria dificuldade de chegar até a mesa. Este era um dos momentos mais esperados. Com a cafeína e a glicose entrando no organismo, a euforia tomava conta do ambiente. As risadas mais altas, o barulho das conversas paralelas. Durante o café, os encontros proliferavam em pequenos encontros dentro do encontro. Cada um desses gestos do durante fazia parte de um grande combo de oferendas e presentes, materiais e imateriais: a música, a comida, a troca, a conversa, a recordação, o acolhimento, as fotos, os afetos, o tempo - o cuidado delas para conosco e nosso com elas.(Trecho de diário de campo)
O momento depois do encontro nas casas era marcado por um sentimento de cansaço, tanto físico como mental. As preocupações deixadas de lado no durante voltavam para o pensamento e o encontro ainda reverberava no caminho de volta para casa, o dito e o não dito.

O silêncio que muito dizia e a linguagem corporal nos deixavam em estado de reflexão. A afetação do encontro provocava em nós a necessidade de elaborar algo que ainda não conseguíamos nomear. Perguntas voltavam a nos ocupar: Será que Luciane vai conseguir resolver o problema com o vizinho dela? Será que chegou bem em casa? Antônia estava tão alheia ao encontro hoje, o que será que aconteceu? O que será que nós, enquanto estudantes de uma universidade pública, participantes de um projeto de extensão, podemos fazer para ajudar Carmen a resolver seu problema? Em que momentos sentimos que foi possível cuidar? O durante reverbera no depois. (Trecho de diário de campo)

Assim, percebemos que o encontro nas casas não se restringia ao estar ou entrar na casa. Diversos agenciamentos aconteciam antes e depois de cada encontro nas casas e eram imprescindíveis. 
$\mathrm{O}$ encontro começava antes mesmo do encontro físico e envolvia um planejamento que era de todas, pois as mulheres também organizavam suas agendas, preparavam o espaço das casas e deixavam um lanche pronto. Em curso, estava a materialização do cuidado de quem ia receber alguém importante. Esses itens do planejamento não eram simplesmente aspectos técnicos do encontro. Neles, havia um exercício de presença e de abertura que possibilitava o cuidado mútuo, acolhendo a

\section{Entrada nas casas}

Figura 1

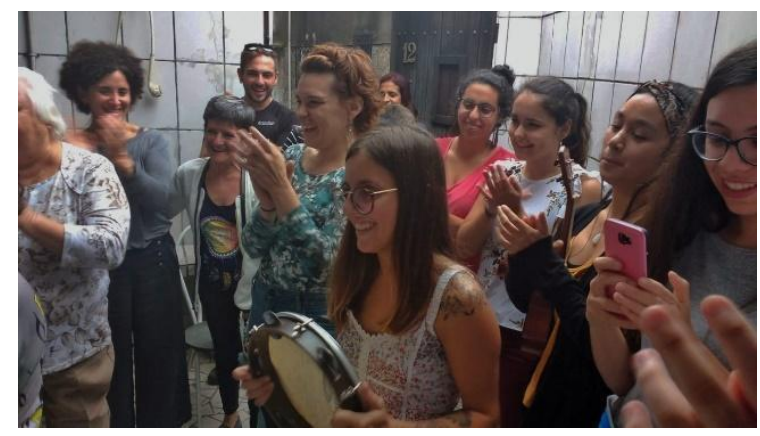

Composições musicais (Registro das autoras)

Para falar de nossa forma de habitar, Hundertwasser desenvolveu a teoria das cinco peles. A primeira das cinco peles é a epiderme que, mais próxima ao nosso corpo, guarda a nossa subjetividade e faz a barreira de Rev. Polis e Psique, 2021; 11(3): 230 - 254 imprevisibilidade que the era inerente. Neste momento e em todo o processo arriscamos a identificar tais micro estratégias como "gestos menores" que, segundo Erin Manning (2019), funcionam como ativadores, portadores do acontecimento, a força capaz de portar a tonalidade afetiva de uma ressonância que pode articular novos modos de existência acolhendo a imprevisibilidade, a força e a sutileza desses encontros.

troca entre o que é nosso e o que é do mundo. A segunda são as roupas, as quais, a partir da cultura, diferenciam a pessoa e o mundo. A terceira pele é o espaço físico da casa, onde se estabelecem as relações que fazem dela uma moradia. O território em que se vive, a comunidade no qual as relações sociais e culturais acontecem é a quarta pele. A camada mais externa, que seria a quinta pele, é o Planeta Terra. As cinco peles são camadas que diferenciam um sujeito de outro e, ao mesmo tempo, os unem (Guzzo, 2020). As diversas camadas que envolvem um indivíduo podem ser vistas como casas, abrigando algo dentro delas, mas comportando também aberturas - poros, margens, janelas e portas, que 
permitem a passagem e a circulação entre si. O corpo, o qual abriga o que há de mais singular no ser, é também uma casa. Uma construção, espaço físico que abriga pessoas, é uma casa. O planeta, que abriga todas as outras camadas, é uma casa. Em alguma dimensão, a casa pode ser um espaço de refúgio que, no entanto, nunca está fechado em si mesmo. Neste sentido, não existe um dentro e um fora - tudo está atravessado por outras camadas.

A partir disso, podemos fazer um paralelo entre a casa e o território existencial descrito por Guattari (1992), em que este território não é apenas geográfico. Trata-se, antes de tudo, de um território relacional, em processo, vivo, sujeito a modificações, em constante relação com outros territórios que o atravessam e produzem sentido (Macerata, Soares \& Ramos, 2014). Assim, pensamos a casa (ou a terceira pele) não apenas como paredes, portas e janelas que abrigam uma família ou grupo de pessoas, mas como um lugar onde relações existenciais são tecidas. Um espaço/tempo que é constantemente atravessado pelas forças internas que constituem aqueles que o habitam e pelas forças externas dos acontecimentos que compõem a comunidade em que está inserido - dos vizinhos mais próximos até as mudanças Rev. Polis e Psique, 2021; 11(3): 230 - 254 sociais, políticas, econômicas e ambientais que a Terra enfrenta. A casa é um território dentro de outro, que influencia e é influenciado por ele a todo momento. Nesta perspectiva, ao entrar em uma casa somos atravessados pelas forças implicadas naquele território existencial. Entramos, mas também passamos a fazer parte, ou seja, produzimos nele uma interferência.

Algumas vezes, no contexto da saúde e da assistência social, as práticas de visita domiciliar são feitas de maneira burocrática, com uma entrada quase forçada nas casas, sem a criação e o fortalecimento de vínculos antes, durante e depois da visita. Oliveira, Kruse, Cicolella e Velleda (2018) dizem que, muitas vezes, profissionais de saúde em visitas domiciliares acabam sendo colocados na posição de agentes estatais, na maneira como agem, conduzem e normatizam as condutas dos sujeitos e comunidades atendidas. Ao entrar nas casas produzemse efeitos e interferências nos territórios existenciais que as constituem. No entanto, por vezes estes são efeitos que geram mais controle e vigilância do que cuidado.

A duração e o tom são diferentes quando comparamos este tipo de visita domiciliar com os encontros "nas casas" aqui relatados. Neles, buscamos operar 
através da lógica do convite: para entrar em uma casa é preciso ser convidado.O convite para entrada nas casas é central no projeto, como percebemos nos trechos abaixo extraídos de diários de campo:

Nosso encontro foi na casa da Fabiana, proposto por ela. Já fomos à casa da Irene muitas vezes, conhecemos a casa da Dona Vera, da Carmen, porém, na casa da Fabiana nunca fomos até aquele dia. A recepção foi maravilhosa, calorosa! Fabi e sua mãe colocam várias cadeiras na garagem, dispostas lado a lado e também frente a frente com uma mesa no fundo coberta por panos de prato escondendo o que havia sido preparado para o nosso café da tarde.(Trecho de diário de campo) Irene nos recebeu em sua casa como a amiga de anos que eu sinto que ela é. Para um anfitrião, percebe-se que existe uma tensão (mesmo que pequena, mas presente) de manter seus convidados saciados de tudo que precisam. Para esse processo não ser estressante, tento sempre manter uma postura de confortabilidade com ações que costumam deixar o anfitrião mais à vontade, como oferecer-me para fazer um café, saber onde as coisas estão - pequenas atitudes que podem deixar o anfitrião mais à vontade. (Trecho de diário de campo)

Nessa experiência, o convite à entrada nas casas era sentido como efeito e, ao mesmo tempo, condição da construção e do cultivo de espaços de intimidade compartilhada. É preciso lembrar que essa partilha entre o grupo não começou "nas casas", na medida em que a própria constituição do grupo teve início em atividades e experiências anteriores, vividas no projeto de Extensão Delicadas Coreografias e, desde 2009, nos módulos curriculares da TS. No entanto, ao sermos convidados a entrar nas casas, ao habitarmos juntos esta camada da pele que compõe o território existencial daquelas mulheres, um novo plano de confiança e partilha foi inaugurado. Fazer parte da composição da experiência de estar em casa tornou-se fundamental no exercício de um cuidado mútuo, alimentado por uma troca afetiva intensa e pela partilha de espaços de intimidade.

\section{Produção de intimidade}


Figura 2

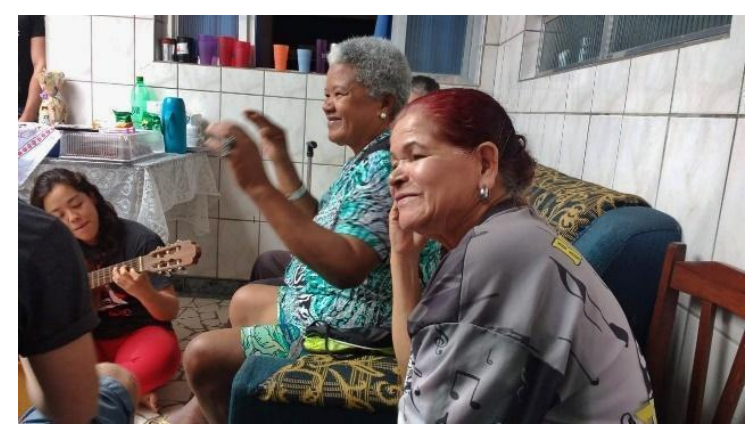

Encontro e intimidade (Registro das autoras)

A situação pandêmica atual, com a qual iniciamos a escrita deste artigo, intensifica e dá visibilidade a muitos traços, desigualdades e contradições que marcam as sociedades contemporâneas. Podemos dizer que a invasão e o ataque aos espaços de intimidade - incluindo a casa - é uma dessas características, epicentro das sociedades do espetáculo, da imagem, da exibição de si (Sibilia, 2016; Brum, 2020). No entanto, o viver inventivo e a produção de saúde requerem a reconfiguração dos espaços de intimidade (Fernández, 2012) e este era um dos desafios que as ações "nas casas" visaram alcançar.

É importante explicitar que não compreendemos o íntimo/intimidade como sinônimos de privado/privacidade. Há uma diferença entre eles. A intimidade pode ser Rev. Polis e Psique, 2021; 11(3): 230 - 254 compartilhada, um momento íntimo pode ser coletivo (Levisky, 2017). Para Fernández (2012), a sociedade industrial burguesa, ao identificar o íntimo como privado, destituiu e prostituiu a intimidade. A autora recorre à etimologia da palavra para marcar uma distinção importante. A palavra intimidade inclui em suas origens o vocábulo "entre", diferentemente do termo privado que está ancorado nos sentidos de "privar", “em segredo", “às escondidas”. A destituição do íntimo pelo privado retira a importância do público e do comunal num momento no qual assistimos globalmente à deterioração e privatização do público (educação, saúde, meios de comunicação, recursos naturais, conhecimento). Para a autora, como consequência, a expansão indiscriminada do privado vai reduzindo tanto a intimidade quanto a comunalidade, "Da intimidade é exigido viver das aparências, e a comunidade é convertida, imaginariamente, em terreno de luta, no qual para que alguém triunfe é necessário conseguir que os demais fracassem" (Fernández, 2012, p. 182).

Em "Para uma Política da Amizade", Ortega (2000) afirma que o público é o lugar da ação no qual o indivíduo age e se diferencia dos outros sujeitos, constituindo sua subjetividade. $\mathrm{O}$ espaço público é um espaço de visibilidade 
da subjetividade - para mostrar-se quem é. Nesse processo de autoconstituição é imprescindível a presença dos outros indivíduos, "Somente na relação com os indivíduos livres através da ação e do discurso é possível para o sujeito se diferenciar, mostrar seu valor e reconhecer-se na alteridade (...)" (Ortega, 2000, p. 28). Portanto, podemos afirmar que a constituição da subjetividade e da intimidade de cada sujeito é compartilhada, é comunal, preservando um espaço comum entre singularidades (Penna \& Dias, 2014). A constituição da subjetividade de um indivíduo se dá em um espaço comum, através da diferenciação relacional.

Assim, nas ações "nas casas" acreditamos que a intimidade é nutrida pela comunalidade e é, ao mesmo tempo, sua condição. De acordo com Fernández (2012), o conceito de comunidade - cum munus - leva-nos a resgatar a noção de munus que refere-se a uma dívida, uma dádiva, um dever em relação aos outros. Ao mesmo tempo, o cum de cum munus é o que vincula, o que junta e faz referência à ação recíproca. Para Fernández, o cum assinala toda forma de proximidades complexas, móveis. Não se reduz a uma justaposição, "É sempre uma proximidade, não somente de trato, mas de ação recíproca, de intercâmbio, de relação ou, ao menos, de exposição mútua" (Fernández, 2012, p. 181). Ao recorrer à definição de Jean-Luc Nancy, Alicia Fernández (2012) pontua que o cum diz de "um respeito a", um levar em conta, um olhar atento ou de interesse, condição de existência de singularidades finitas. Assim, comunalidade e intimidade não estão divorciadas. Diferentemente, nutrem-se mutuamente e é esta relação que buscamos fortalecer no projeto "nas casas", considerando sua importância na produção de cuidado e saúde.

Alicia Fernández (2012) presenteianos, ainda, com a lembrança de que a palavra "intimidade", quando se torna o verbo "intimar", remete a três acepções: fazer saber alguma coisa; introduzir-se uma matéria pelos poros ou espaços vazios de outra; introduzir-se no afeto e alma de alguém. O desafio passa a ser, portanto, a construção de espaços "prazenteiros de intimidade compartilhada" (Fernández, 2012, p. 178) - territórios que possibilitem a relação entre intimidade e comunalidade e seus efeitos na produção de cuidado. A partir dos exercícios de escuta atenciosa, partilha respeitosa da palavra e do vivificar os corpos pelos cantos, pelas danças, pelo lanche coletivo e pelos silêncios acompanhados, buscou-se construir espaços compartilhados de intimidade e 
cuidado. Os encontros realizados "nas casas" constituíram-se, portanto, como espaços e tempos de construção de comunalidade e intimidade.

Chegando à casa da Carmen, nos cumprimentamos com abraços, perguntamos “como você está?", puxamos assunto. Eu vejo tudo isso como um reflexo da intimidade, da relação de confiança que aos poucos se torna mais visível e de laços nitidamente delicados que se instalaram ali, sem que parássemos para sentir todo este processo. É lindo de se ver e sentir. As brincadeiras surgem sem dar oportunidade ao silêncio e ali nos damos conta de que parece, por um momento, que o tempo não passa e, de repente, a mesma harmonia está de volta.(Trecho de diário de campo)

\section{O grupo e a produção de intimidade e comunalidade}

Figura 3

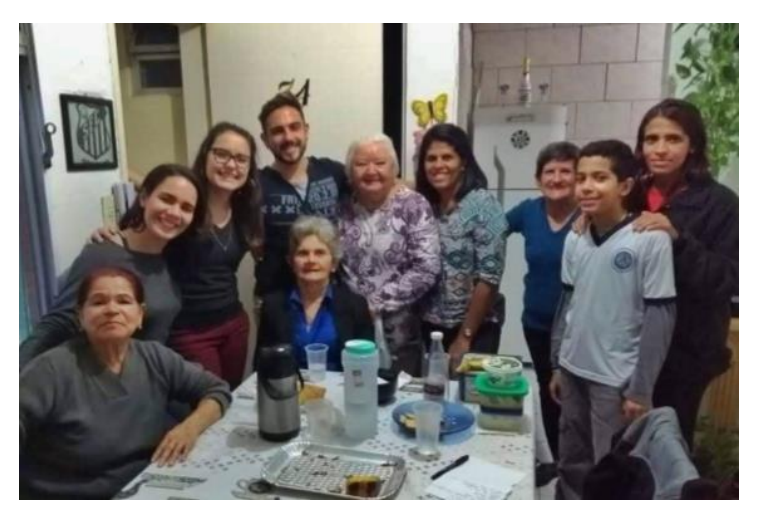

Grupo de mulheres (Registro das autoras)

Para Pichon-Rivière (1983), cada participante de um grupo se apresenta com sua verticalidade, sua história pessoal, seja ela consciente ou não. Na medida em que o grupo se estabelece, passa-se a ter um objetivo comum, e com isso aparecem as horizontalidades, as necessidades grupais, as quais são mais que apenas a somatória das verticalidades, mas sim o resultado de sua interação, criando uma identidade grupal. Para o autor, a partir desse sentimento de identificação e pertença grupal, os integrantes do grupo vão deixando a posição de espectadores e passando para a posição de protagonistas. Todavia, nas ações "nas casas", no grupo com as mulheres e as universitárias, tínhamos por desafio a construção de transversalidade, tal como conceituada por Guattari (2004). Para além da horizontalidade e da verticalidade, no grupo não buscávamos superar diferenças e criar uma igualdade identitária niveladora entre todas as participantes, mas cultivar um plano de diferenciação, evidenciando a sua polifonia constitutiva.

$$
\begin{aligned}
& \text { Juquinha nos contou que às vezes } \\
& \text { não se sentia parte do grupo pois } \\
& \text { ela falava alto com muitos }
\end{aligned}
$$


palavrões e as outras pessoas do grupo não seguiam na mesma linha, disse que na escola que ela toca (música) todos são parecidos com ela e no grupo (com as mulheres) não. Me pareceu uma questão de pertencimento. Por não ver os outros indivíduos como parecidos com ela, Juquinha sentia um distanciamento do resto do grupo. (Trecho de diário de campo)

Como já apontamos, a intimidade não é oposta da comunalidade, tampouco separada desta; pelo contrário, elas nutremse mutuamente, o que permitiu a Juquinha fazer-ser-parte, aproximar-se de si e das outras participantes em um deslocamento complexo, metaestável. A intimidade e a comunalidade são experimentadas no entre jogo de proximidades e distanciamentos, resultantes e produtores de processos de afetação mútua. No decorrer dos encontros, foi possível experimentar juntos que, à medida que compartilhamos espaços de intimidade, a igualdade ou semelhança deixa de ser critério de pertencimento, dando espaço para algo muito mais interessante: a constituição de espaços partilhados nos quais a diferenciação é efeito e condição. Nestes espaços, Juquinha é afetada pelos acontecimentos do grupo e afeta, produzindo reposicionamentos subjetivos que potencializam a diferenciação com e no grupo (Passos, Kastrup \& Tedesco, 2013). Assim, o sentimento inicial, expresso no trecho do diário acima, pode ser reposicionado a cada encontro vivido, na medida em que se experimentava o acolhimento daquilo que difere e compõe a polifonia grupal.

Como vimos anteriormente, no trabalho com as mulheres, a possibilidade de afetação mútua era cultivada através de um processo de aquecimento e construção de disponibilidade antes, durante e depois dos encontros, tanto pelas universitárias quanto pelas mulheres que abriam suas casas para receber e acolher o grupo. Estes processos de construção de disponibilidade e abertura materializavam-se em pequenos gestos e deslocamentos: nas conversas e na sustentação dos silêncios; nos momentos em que mesmo com a dificuldade de locomoção e limitações físicas fazia-se um esforço para estar presente; no cuidado da anfitriã que preparava a casa e o lanche a ser partilhado; na atenção e no esforço para que todas se sentissem confortáveis. Todo este processo reverbera no desenrolar do encontro, possibilitando a vivência de uma experiência comunal não protocolar, avessa aos automatismos que limitam a 
partilha e a tessitura da intimidade. Nestes momentos, o grupo conseguia fazer-se grupo e a responsabilidade do cuidado e do manejo não ficava a cargo apenas das extensionistas, distribuindo-se para todos os envolvidos na experiência, como é possível ver no recorte do diário de campo a seguir.

A forma como ela (uma das mulheres do grupo) foi acolhida por todos foi emocionante, fez com que as lágrimas viessem. A Dona Vera e a Dona Antônia disseram que se ela precisasse, poderia ficar na casa delas por um tempo. Esta última falou que elas poderiam beber e comer o dia inteiro, já que o filho só chega à noite. As mulheres sugeriram que ela revezasse entre as casas e garantiram que ela não ficaria sem lugar para morar. Acredito que nada que falássemos (nós, da UNIFESP) seria tão acolhedor quanto o que as próprias mulheres falaram. Me fez sentir a maturidade do grupo delas... (Trecho de diário de campo)

Em certo sentido, esta "maturidade" sentida pela extensionista diz Rev. Polis e Psique, 2021; 11(3): 230 - 254 da delicadeza que perpassava os gestos de cuidado em alguns encontros. No entanto, esta qualidade não era garantida e isenta de cultivo e esforços. Nem sempre era possível realizar o encontro na casa de alguma delas e/ou com a presença de todas. Algumas têm limitações físicas que acarretam em problemas de locomoção. O difícil acesso à região e a falta de transporte oferecido pela universidade também dificultavam o acontecimento dos encontros. A falta de comunicação entre as mulheres, as estudantes e as extensionistas, às vezes, também era um problema.

A produção de intimidade promovida pelo projeto encontrava dificuldades em seu caminho que, por vezes, pareciam enfraquecer sua potência, mas que produziam inúmeros aprendizados. Será que a produção de intimidade e cuidado não é também composta pelos desafios que nos afetam?

Sem dúvida alguma eu posso afirmar que este encontro foi $o$ mais denso que presenciei e cada vez mais eles me fazem refletir que o projeto Delicadas Coreografias é vivido com pessoas e suas fragilidades, e a delicadeza está justamente dada por esta condição. A agradabilidade do encontro não 
se dá através de momentos e sentimentos bons o tempo todo, mas da variedade de sensações, altos e baixos que fazem parte desse processo - do qual não podemos esquecer em momento algum - chamado vida. É parte do processo entender que ocorrem mil e uma coisas durante os quinze dias em que não há encontro e que não podemos desprezar esses acontecimentos apenas na tentativa de pensar o momento da quartafeira e nas atividades propostas. Há processos de sofrimento, limitações (físicas ou não) e também há muita alegria, superações, conquistas, sonhos realizados. Complexidades que fazem parte da vida real: a presença, a disponibilidade, a felicidade, a tristeza, a ausência, a vitória, a enfermidade, a morte, o afeto e o desafeto, o carinho, a necessidade de acolhimento, a amizade.(Trecho de diário de campo)

\section{Intimidade e cuidado}

Almeida e Caldas (2012), ao analisarem a relação entre intimidade e saúde, concluem que o estado de saúde está ligado à qualidade dos vínculos formados: bons valores de intimidade estariam ligados a um melhor estado de saúde e qualidade de vida (Almeida \& Caldas, 2012). O vínculo aparece algumas vezes entre as diretrizes operacionais do Sistema Único de Saúde brasileiro (SUS) como componente da necessidade de saúde dos usuários. A Política Nacional de Atenção Básica aponta que o vínculo “[...] consiste na construção de relações de afetividade e confiança entre o usuário e o trabalhador da saúde, permitindo o aprofundamento do processo de corresponsabilização pela saúde, construído ao longo do tempo, além de carregar, em si, um potencial terapêutico." (Portaria $\mathrm{n}^{\circ}$ 2436, 2017). No cuidado em saúde a criação de vínculos possibilita que um plano de participação seja efetivamente experimentado, dando condições de possibilidade para que as experiências dos trabalhadores e usuários sejam postas lado a lado. Assim, cria-se espaço para que o usuário participe das decisões sobre seu processo de cuidado junto com a equipe que o atende e, assim, ser protagonista do seu próprio cuidado. (Seixas et al, 2019).

Seixas et al (2019) nos dizem que o vínculo no trabalho em saúde deve ser construído continuamente entre trabalhadores e usuários, resultando em um 
lugar de confiança para ambos, que possibilita, inclusive, um melhor conhecimento dos problemas enfrentados pela população atendida. Ao legitimar o discurso do outro sobre seu modo de vida, desejos e experiências, este se sente reconhecido e abre caminho para que possa validar o nosso discurso também - por mais diferente que esses discursos sejam, em uma relação de reconhecimento mútuo. São justamente as diferenças que colocam em simetria os discursos e saberes do usuário e do trabalhador, corresponsabilizando os dois pelo cuidado. Nas palavras de Seixas et al:

Assim, as diferenças entre os sujeitos envolvidos não operaram na constituição de uma assimetria entre eles, não produziram na trabalhadora ou no usuário um sentimento de repulsa do outro, mas sim de simetria. Nessas relações nas quais os envolvidos, nas suas diferenças, consideram-se interlocutores válidos - seja o usuário pelo trabalhador ou viceversa - é possível que se estabeleça uma relação de simetria, não como harmonia e igualdade, mas como dissolução das fronteiras entre os interlocutores, sem negar singularidades, nem passar por cima do fato de que há diferenças. (Seixas et al, 2019, pp. 6-8)

Nas ações "nas casas”, experimentamos o cultivo do respeito e interesse mútuos que permite a diferenciação. As estudantes - vindas em sua maioria de outro território, outra classe social, outra geração, munidas de um saber acadêmico elitista - encontravam o grupo de mulheres e adentravam o seu território. Ao entrar em contato com a diferença, muitas vezes experimentavam um estado desconfortável de "não saber", de sentirem-se deslocadas e desterritorializadas. $\mathrm{O}$ saber da universidade parecia não ajudá-las a descobrir "o que dizer" ou "o que fazer". Seixas et al (2019) nos dizem ser impossível saber "o que fazer", uma vez que a produção se dá no encontro. É no encontro que a simetria entre o discurso do cuidador e o do que é cuidado mostra as possibilidades do "o que fazer". A presença e a implicação no encontro geram uma afetação mútua, efetivando-se como um exercício de cuidado. E é através da construção de espaços partilhados de intimidade que se tornou possível acolher o não saber, abrindo espaço para o fazer 
COM, o cuidar COM, o saber e o sentir COM, fundamentais no exercício do cuidado.

\section{Considerações Finais}

Durante a escrita deste artigo fomos atravessados pela pandemia de COVID-19, portanto, de forma peculiar, analisamos experiências que ocorreram nas casas em um período em que muitos de nós estávamos forçados a ficar em casa. Nesse período, mas não só ao longo dele, experimentamos mudanças nos espaços de intimidade, sendo a casa um deles. O trabalho proposto caminhou na direção de reconfigurar os espaços de intimidade para produzir um cuidado em saúde por meio de visitas às casas de um grupo de mulheres.

Um ponto a se destacar é que os encontros tinham um tom próprio e uma peça chave para que ocorressem: o convite. Analisamos, aqui, a intimidade ao adentrar uma casa, como ela se fortalece e se relaciona com o cuidado, as delicadezas dos pequenos gestos que guiam as ações e a sutileza de seus efeitos, mas sem esquecer que nos encontros promovidos já havia um vínculo pré-estabelecido e uma vontade da anfitriã em receber aquele grupo. As visitas às casas das mulheres ofereceram a manutenção e o Rev. Polis e Psique, 2021; 11(3): 230 - 254 aprofundamento de um processo e vínculo já cultivado no grupo, ampliando, em muitos casos, as relações existentes ou mesmo criando novos ordenamentos no convívio das alunas e das mulheres.

Nas experiências "nas casas", a intimidade era construída em vários planos relacionais: entre as estudantes e as mulheres; as estudantes entre si; as mulheres entre si; entre as estudantes e o território; no trajeto para chegar às casas; e entre cada uma consigo mesma. Tudo isso envolvia um processo delicado de acesso e invenção de modos conjuntos de ser e estar, o cultivo da confiança e do pertencimento. A afetação se torna presente e alimenta todas estas dimensões de produção de proximidade e intimidade e se materializa nas atitudes, no estar atenta e interessar-se umas pelas outras.

Parte do processo enfrentado pelas estudantes que participaram do projeto de extensão, e consequentemente das ações "nas casas", era adentrar um novo território e conhecer as relações nele estabelecidas, assim como afetar e ser afetada por ele. Percebeu-se um processo de reconhecimento e produção de diferenciação: não para superá-la, em uma tentativa de apagá-la; mas sim de sustentála, cultivá-la e experimentar nela potência. $\mathrm{Na}$ diferença de território - geracional, de 
classe social, de raça, de gênero, de orientação sexual - entre as estudantes e as mulheres cultivou-se uma potente forma de cuidado. É no encontro entre diferentes, na polifonia, na implicação e afetação mútua, na construção e sustentação permanente da confiança e da intimidade, reconhecendo e qualificando cada pequeno deslocamento, que o cuidado tem a chance e a delicadeza de acontecer.

Por fim, arriscamos dizer que a situação pandêmica atual explicita de forma brutal a importância de modos de cuidar cuja potência encontra-se nesta tessitura relacional, no ater-se aos pequenos gestos e deslocamentos. Ao escancarar a vulnerabilidade e precariedade da vida humana (Liberman, Guzzo\& Lima, 2020), a pandemia demonstra que a força da vida não se sustenta ou torna-se extremamente frágil sem partilha atenciosa e respeitosa e esta é a direção de cuidado que buscamos afirmar.

\section{Referências}

Almeida, L. M. M. F. \& Caldas, J. M. P. (2012). Intimidade e saúde. Psicologia USP, 23 (4), 737-755. doihttps://doi.org/10.1590/S0103$\underline{65642012000400007 .}$.

Barros, M. (2008). Memórias inventadas. São Paulo, Brasil: Planeta do Brasil.
Brum, E. (2020). Quando o vírus nos trancou em casa, as telas nos deixaram sem casa. El País. Recuperado de https://brasil.elpais.com/opiniao/202 0-12-23/quando-o-virus-nos-trancouem-casa-as-telas-nos-deixaram-semcasa.html.

Capozzolo, A. A., Casetto, S. J. \&Henz, A. O. (2013).Clínica Comum: itinerários de uma formação em saúde. São Paulo, Brasil: Hucitec.

Fernández, A. (2012). A Atenção aprisionada: psicopedagogia da capacidade atencional. Porto Alegre, Brasil: Penso.

Governo Federal, Ministério da Mulher, da Família e dos Direitos Humanos. (2020).

Coronavírus: sobe o número de ligações para canal de denúncia de violência doméstica na quarentena. Recuperado de https://www.gov.br/mdh/ptbr/assuntos/noticias/20202/marco/coronavirus-sobe-o-numerode-ligacoes-para-canal-de-denunciade-violencia-domestica-naquarentena.

Guattari, F. (1992). Caosmose. São Paulo, Brasil: Ed 34.

Guattari, F. (2004). Psicanálise $e$ transversalidade: ensaios de análise institucional. São Paulo, Brasil: Ideias e Letras. 
Guzzo, M. (2020). Notas sobre corpo, narrativa e território: as várias peles da presença.

In P. M. Goulart \& M. L. Pezzato (Orgs.), Narrativas de si: práticas em educação e saúde (pp. 99-106). Porto Alegre, Brasil: Editora Rede Unida.

Hundertwasser, F. (1998). The Five Skinsof Man [tinta sobre papel]. Namida AG.

Recuperado de

https://www.researchgate.net/figure/Friede nsreich-Hundertwasser-The-Five-

Skins-of-Man-1998-Ink-on-paper297-cm-x-209_fig1_317027716.

Levisky, R. B. (2017). Expressões da intimidade nos vínculos: interferências da cultura. Ide, 39 (63), 41-58. Recuperado de http://pepsic.bvsalud.org/scielo.php? script $=$ sci_arttext\&pid=S0101$\underline{31062017000100004 \& \operatorname{lng}=p t \& t \operatorname{lng}=}$ pt.

Liberman, F. \&Maximino, V. (2015). Planos grupais e experiência estética: friccionando

ideias, emoções e conceitos. In F. Liberman \& V. Maximino (Orgs.),Grupos e terapia ocupacional: formação, pesquisa e ações (pp. 115-127). São Paulo, Brasil: Summus Editorial. Recuperado de https://335ba2e8bd82-4670-a42f-

c1df1b62a515.filesusr.com/ugd/c657 6e 59b65e7317ec47ab8d92ab49ebea df74.pdf.
Liberman, F. \&Maximino, V. (2016). Acessibilidade e experiência estética: um trabalho com

mulheres em situação de vulnerabilidade.Cad. Ter. Ocup. UFSCar, 24 (1), 139-146. doi: http://doi.editoracubo.com.br/10.432 2/0104-4931.ctoRE0671.

Liberman, F., Guzzo, M \& Lima, E. M. F. A. (2020). Pequenos deslocamentos: corpo, arte,

saúde e educação.Revista Educação, Artes e Inclusão, 16 (4), 196-215. doi: http://dx.doi.org/10.5965/198431781 $\underline{642020196}$

Macerata, I., Soares, J. G. N. \& Ramos, J. F. C. (2014). Apoio como cuidado de territórios existenciais: Atenção Básica e a rua. Interface (Botucatu), 18 919-930. doihttps://doi.org/10.1590/1807$\underline{57622013.0210}$

Manning, E. (2019). Proposições para um movimento menor. Moringa Artes do Espetáculo UFPB, 10 (2), 11-24. Recuperado de https://periodicos.ufpb.br/ojs/index.p $\mathrm{hp} /$ moringa/article/download/49811/ $\underline{28984 /}$

Oliveira, S. G., Kruse, M. H. L., Cicolella, D. A. \&Velleda, K. L. (2018).

Visita domiciliar no Sistema Único de Saúde: estratégia da biopolítica. Revista

Uruguaya de Enfermería, 13 (1), 9-21. doi: https://doi.org/10.33517/rue2018v13 n1a2. 
Ortega, F. (2000). Para um política da amizade: Arendt, Derrida, Foucault. Rio de

Janeiro, Brasil: RelumeDumará.

Passos, E., Kastrup, V. \&Tedesco, S. (2013). Editorial, Fractal: Rev. Psicologia, 25 (2), 217-220. doi: https://doi.org/10.1590/S1984$\underline{02922013000200001}$

Penna, J. C. \& Dias, A. M. (2014). Comunidades sem fim.Rio de Janeiro, Brasil: Circuito.

Pichon-rivière, E.(1993). $O$ processo grupal. São Paulo, Brasil: Martins Fontes.

Picinni, A. \& Araújo, T. (2020). Violência Doméstica no Brasil: desafios do isolamento. Politize!'Recuperado de: https://www.politize.com.br/violenci a-domestica-no-brasil/

Portaria $\mathrm{n}^{\mathrm{o}}$ 2.436, aprova a Política Nacional de Atenção Básica, estabelecendo a revisão de diretrizes para a organização da Atenção Básica, no âmbito do Sistema Único de Saúde (SUS). Ministério da Saúde. (2017). Recuperado de https://bvsms.saude.gov.br/bvs/saude legis/gm/2017/prt2436_22_09_2017. html.

Seixas, C. T., Baduy, R. S., Cruz, K. T., Bortoletto, M. S. S., Slomp Junior, H. \&Merhy, E. E. (2019). O vínculo como potência para a produção do cuidado em Saúde: o que usuários- guia nos ensinam. Interface Comunicação, Saúde, Educação, 23, e170627. doi: https://doi.org/10.1590/interface.170 $\underline{627 .}$

Sibilia, P. (2016). O show do Eu: a intimidade como espetáculo. Rio de Janeiro, Brasil: Contraponto.

Silva, C. (2020). Sete verbos para se conjugar o morar. $N-1$ edições. Recuperado de

https://www.n-1edicoes.org/textos/82

Sombini, E. (2020, 19 dez). Ilustríssima Conversa: Brasil institucional vive em guerra com a brasilidade, diz Luiz Simas [áudio podcast]. Recuperado de https://omny.fm/shows/ilustr-ssimaconversa/brasil-institucional-viveem-guerra-com-a-brasilid

Souza, S. \& Francisco, A. L. (2017) Aproximações entre fenomenologia e o método da cartografia em pesquisa qualitativa.Atas Investigação Qualitativa em Saúde, 2, 120-129.Recuperado de https://proceedings.ciaiq.org/index.p hp/ciaiq2017/article/view/1201/1162

Beatriz Borges de Oliveira é graduanda em Psicologia pela Universidade Federal de São Paulo.

E-mail: beatriz.borges@ unifesp.br ORCID:https://orcid.org/0000-0002-3697$\underline{9826}$ 
Flávia Liberman é professora associada do Curso de Terapia Ocupacional, no Programa de Pós-graduação Ensino em Ciências da Saúde e no Programa Interdisciplinar em Ciências da Saúde da Universidade Federal de São Paulo, Departamento de Saúde, Clínica e Instituições.

E-mail: f.liberman@unifesp.br

ORCID:https://orcid.org/0000-0001-8563$\underline{5993}$

Luciana Vieira Caliman é professora licenciada do Departamento de Psicologia e do Programa de Pós-graduação em Psicologia Institucional da Universidade Federal do Espírito Santo. É também professora adjunta convidada da Escola Superior de Educação de Lisboa, Portugal. E-mail: calimanluciana@ gmail.com ORCID:https://orcid.org/0000-0001-8558$\underline{6562}$

Submissão: $10 / 02 / 2021$

$1^{\circ}$ avaliação: 22/02/2021

$2^{o}$ avaliação:10/05/2021

$3^{o}$ avaliação: 28/06/2021

Aceite: $19 / 10 / 2021$ 